\title{
Preparation of Boron Doped Fullerene Film by a Thermal Evaporation Technique using Argon Plasma Treatment and Its Electrochemical Application
}

\author{
Arenst Andreas Arie ${ }^{1,2}$, Bup Ju Jeon ${ }^{2}$ and Joong Kee Lee ${ }^{1,2, \wedge}$ \\ ${ }^{1}$ Battery Research Center, Korea Institute of Science and Technology, Seoul 130-650, Korea \\ ${ }^{2}$ Dept. of Energy Resources, Hanbuk University, Dongducheon, Gyeonggi-do, 483-777, Korea \\ ${ }^{3}$ Energy Conversion Technology Division, University of Science and Technology, Daejeon 305-333 Korea \\ ‘e-mail: leejk@kist.re.kr \\ (Received May 14, 2010; Accepted June 16, 2010)
}

\begin{abstract}
Boron doped fullerene $\mathrm{C}_{60}\left(\mathrm{~B}_{\mathrm{B}} \mathrm{C}_{60}\right)$ films were prepared by the thermal evaporation of $\mathrm{C}_{60}$ powder using argon plasma treatment. The morphology and structural characteristics of the thin films were investigated by scanning electron microscope (SEM), Fourier transform infra-red spectroscopy (FTIR) and x-ray photo electron spectroscopy (XPS). The electrochemical application of the boron doped fullerene film as a coating layer for silicon anodes in lithium ion batteries was also investigated. Cyclic voltammetry $(\mathrm{CV})$ measurements were applied to the $\mathrm{B}: \mathrm{C}_{60}$ coated silicon electrodes at a scan rate of $0.05 \mathrm{mVs}^{-1}$. The $\mathrm{CV}$ results show that the $\mathrm{B}: \mathrm{C}_{60}$ coating layer act as a passivation layer with respect to the insertion and extraction of lithium ions into the silicon film electrode.
\end{abstract}

Keywords : Boron, Doping, Fullerenes, Plasma, Lithium ion battery

\section{Introduction}

Since the invention of Fullerene $\mathrm{C}_{60}$ by Kroto in 1985 [1], $\mathrm{C}_{60}$ and its derivatives have been used in various applications, including solar cells [2], light emitting diodes [3] and hydrogen storage [4], due to their unique structure and properties. Pure $\mathrm{C}_{60}$ films are semiconductor materials possessing a band-gap of $1.5 \mathrm{eV}$ and an electrical resistivity of $10^{3}-10^{8} \Omega \cdot \mathrm{cm}$ at room temperature. In order to improve the conductivity of $\mathrm{C}_{60}$ films, boron atoms can be introduced into the $\mathrm{C}_{60}$ lattices. The preparation of boron doped $\mathrm{C}_{60}$ films was firstly reported by Zou et al. $[5,6]$, however no applications were proposed in their works.

In this study, the boron doped $\mathrm{C}_{60}$ films were prepared by the thermal evaporation of $\mathrm{C}_{60}$ powder using argon plasma treatment. The electrochemical application of the film is then introduced. Specifically, the boron doped $\mathrm{C}_{60}$ film was used as a coating layer for silicon anodes in lithium secondary batteries. Furthermore, the effect of argon plasma treatment on the structural and electrochemical characteristics of the coated silicon electrodes was also investigated.

\section{Experimental}

For the deposition of the thin film, $\mathrm{C}_{60}$ powder was loaded into a tungsten boat, as depicted in Fig. 1. The substrate was located on a steel holder and placed about $10 \mathrm{~cm}$ from the boat. The substrates were a silicon wafer for the structural

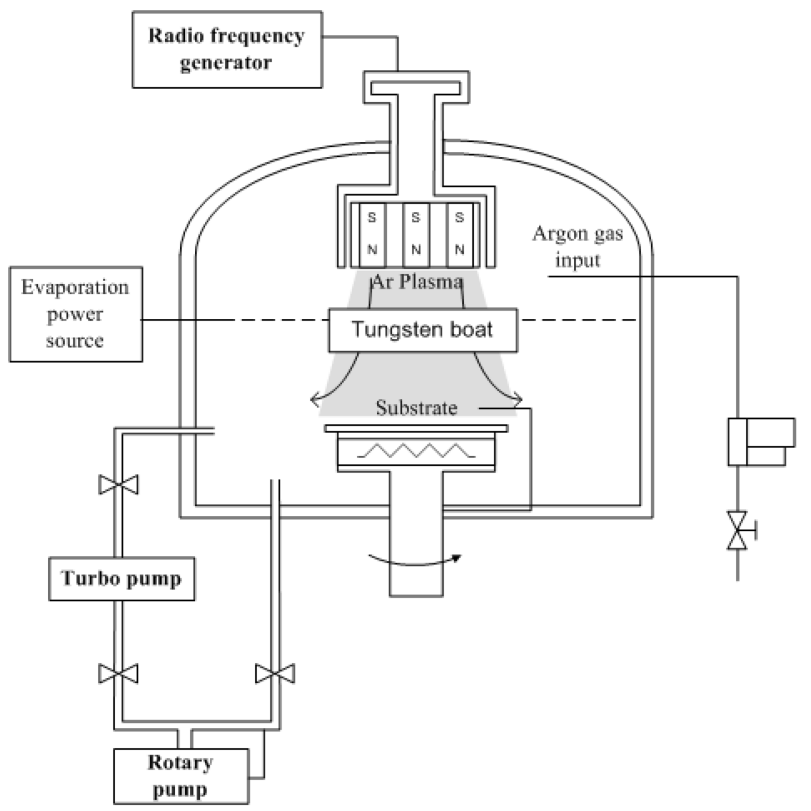

Fig. 1. Schematic diagram of thermal evaporation system to prepare the $\mathrm{B}: \mathrm{C}_{60}$ films. 
studies and a silicon film on $\mathrm{Cu}$ foil for the electrochemical tests. Firstly, the pressure inside the chamber was reduced to a base pressure of $10^{-5}$ Torr using a rotary pump. After that, a mixture of argon and diborane $\left(\mathrm{B}_{2} \mathrm{H}_{6}\right)$ was entered into the chamber with a flow rate of $30 \mathrm{sccm}$ (standard cubic centimeters) to reach a working pressure of $2.5 \cdot 10^{-2}$ Torr. The flow rate was adjusted by a mass flow controller (MFC). Then, the radio-frequency generator was activated to generate the argon plasma. At the same time, the $\mathrm{C}_{60}$ powder was evaporated by thermal heat input. The resulting $\mathrm{C}_{60}$ vapor in the argon plasma environment was deposited in the form of a thin film on the substrate and the boron atoms were inserted into the fullerene film lattices. The substrate temperature was set at $150^{\circ} \mathrm{C}$ and a plasma power of $100 \mathrm{~W}$ was used during the deposition process. For the comparison study, a pristine $\mathrm{C}_{60}$ film was also deposited by the thermal evaporation of $\mathrm{C}_{60}$ powder. The evaporation was done under the same conditions as that used for the $\mathrm{B}$ : $\mathrm{C}_{60}$ film without the argon plasma treatment.

The surface morphology and structure of the thin films were examined by scanning electron microscope (SEM), Fourier transform infra red spectroscopy (FTIR, Nicolet Almega XR, Thermo Electron Corporation) and x-ray photo electron spectroscopy (XPS, VG Scientific ESCALAB 200R). The electrochemical characteristics were studied by cyclic voltammetry $(\mathrm{CV})$ measurements at a scan rate of $0.005 \mathrm{mVs}^{-1}$ within a cut-off voltage range of $0 \sim 3 \mathrm{~V}$. For the $\mathrm{CV}$ tests, half cells were then fabricated in a dry room. The half-cells were fabricated by sandwiching a polyethylene (PE) separator between the $\mathrm{B}: \mathrm{C}_{60}$ coated $\mathrm{Si}$ film electrode (as the working electrode) and $\mathrm{Li}$ metal (as the counter electrode). The half-cell $(2 \mathrm{~cm} \times 2 \mathrm{~cm})$ was then sealed in an aluminized polyethylene bag. The electrolyte was $1 \mathrm{M} \mathrm{LiPF}_{6}$ in a mixture of ethylene carbonate (EC), ethyl methyl carbonate (EMC) and dimethyl carbonate (DMC) $(1: 1: 1$ by volume).

\section{Results and Discussion}

Fig. 2 a shows the SEM photographs of the pristine $\mathrm{C}_{60}$ film synthesized by the thermal evaporation technique without argon plasma treatment. From the surface view, it can be seen that the film consists of many grains with different sizes, due to the evaporation of the $\mathrm{C}_{60}$ powder. In contrast, the $\mathrm{B}: \mathrm{C}_{60}$ film shows a smaller grain size with a more uniform shape, as depicted in Fig. 2 b. It seems that the insertion of the boron atoms assisted by the argon plasma treatment during the deposition of the film contributes to the smaller grain size of the $\mathrm{B}: \mathrm{C}_{60}$ film. From the cross-sectional SEM image in Fig. 2 c, the thickness of the $\mathrm{B}: \mathrm{C}_{60}$ film is estimated to be $100 \mathrm{~nm}$.

Fig. 3 shows the Raman spectra of the pristine $\mathrm{C}_{60}$ film deposited by the evaporation technique without argon

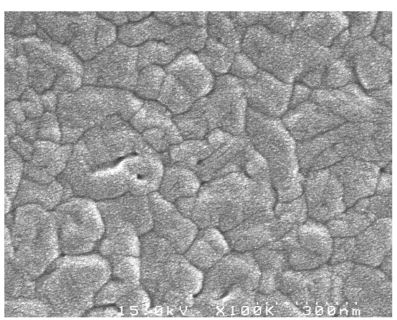

(a)

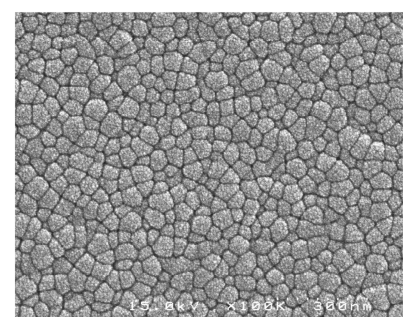

(b)

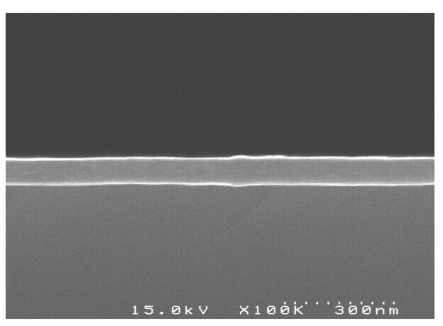

(c)

Fig. 2. Surface view SEM image of the (a) pristine $\mathrm{C}_{60}$, (b) $\mathrm{B}: \mathrm{C}_{60}$ thin film and (c) its cross-sectional view.

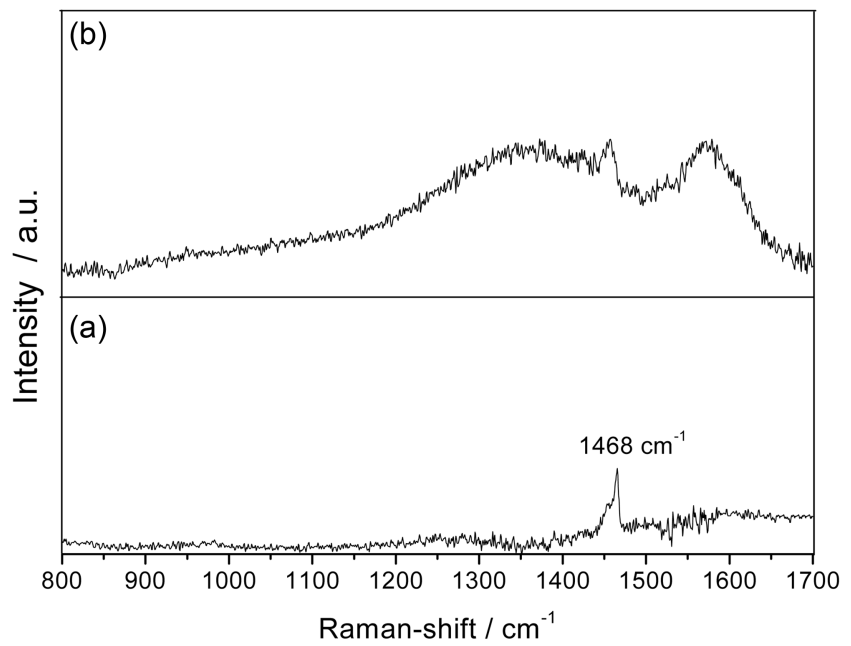

Fig. 3. Raman spectra of the as deposited (a) pristine $\mathrm{C}_{60}$ and (b) $\mathrm{B}: \mathrm{C}_{60}$ thin film.

plasma treatment and the $\mathrm{B}: \mathrm{C}_{60}$ film synthesized with argon plasma treatment. It can be seen that a strong peak at Raman shift of $1468 \mathrm{~cm}^{-1}$, known as the pentagonal pinch mode, is observed in the case of pristine $\mathrm{C}_{60}$ film $[7,8]$. However, this pentagonal pinch mode are gradually separated and broadened but its existence is still recognized in the case of $\mathrm{B}: \mathrm{C}_{60}$ films. This broadened peak in the vicinity of pentagonal pinch is the main indication of the typical fullerene $\mathrm{C}_{60}$ structure, which can not be found in other structure of carbon such as graphite, diamond or carbon nano-tubes [9-12].

Fig. 4 shows the FTIR spectra of the pristine $\mathrm{C}_{60}$ film deposited by the evaporation technique without argon 


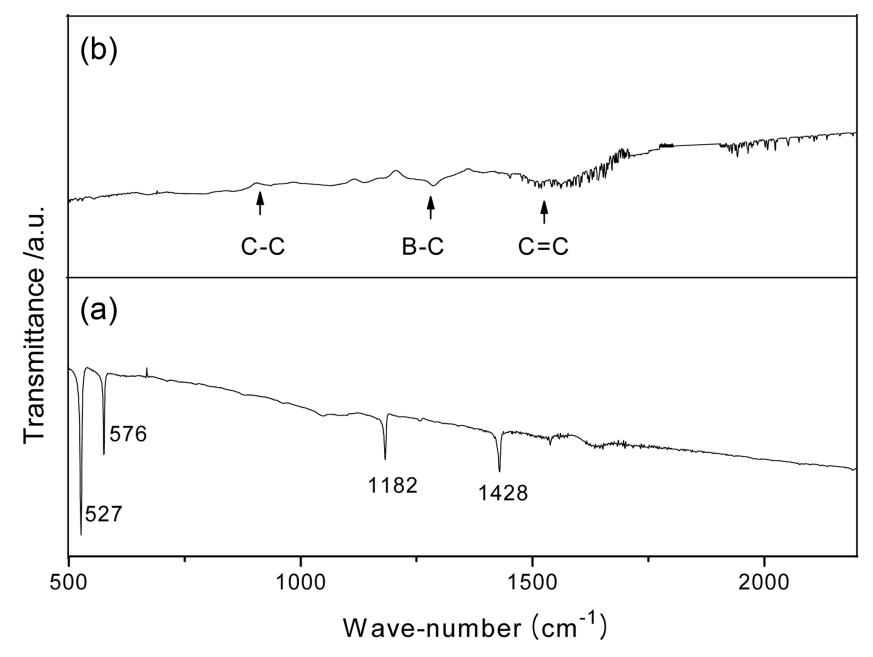

Fig. 4. FTIR spectra of the as deposited (a) pristine $\mathrm{C}_{60}$ and (b) $\mathrm{B}: \mathrm{C}_{60}$ thin film.

plasma treatment and the $\mathrm{B}: \mathrm{C}_{60}$ film synthesized with argon plasma treatment. In the case of the pristine $\mathrm{C}_{60}$ film, there are four dominant peaks detected at wave-numbers of 511, 527,1182 and $1428 \mathrm{~cm}^{-1}$. However, these four peaks are not found in the spectrum of the $\mathrm{B}: \mathrm{C}_{60}$ film, in which many new peaks related to the vibration of the bonding states of C-C, $\mathrm{C}=\mathrm{C}$ and $\mathrm{B}-\mathrm{C}$ are observed. Therefore, the bonding between boron and carbon in the $\mathrm{B}: \mathrm{C}_{60}$ film can be detected, due to the presence of the weak vibration of the $\mathrm{B}-\mathrm{C}$ bond located at a wave-number of $1260 \mathrm{~cm}^{-1}$.

Fig. 5a shows the $C 1 \mathrm{~s}$ XPS spectra of the pristine $\mathrm{C}_{60}$ and $\mathrm{B}: \mathrm{C}_{60}$ films. The $\mathrm{C} 1 \mathrm{~s}$ binding energies of the pristine $\mathrm{C}_{60}$ and $\mathrm{B}: \mathrm{C}_{60}$ films are determined as to be 284.2 and $285.2 \mathrm{eV}$, respectively. The binding energy in the $\mathrm{B}: \mathrm{C}_{60}$ film is shifted to a higher value, due to the presence of stronger bonding between the carbon molecules. The full width at half maximum (FWHM) of the $\mathrm{C} 1 \mathrm{~s}$ peak for the $\mathrm{B}: \mathrm{C}_{60}$ films is determined to be $1.58 \mathrm{eV}$. This value is obviously larger than that of the pristine form $(0.96 \mathrm{eV})$. This higher FWHM value and broader spectrum of the $\mathrm{B}: \mathrm{C}_{60}$ films indicates that the linking among the fullerene molecules takes place during the deposition process. The presence of boron atoms in the fullerene lattices is evidenced by the B 1s XPS spectra of the $\mathrm{B}: \mathrm{C}_{60}$ film, as shown in Fig. $5 \mathrm{~b}$. The peak centered at $189.4 \mathrm{eV}$ is an indication of the bonding between boron and carbon in the fullerene film, which is consistent with the spectra found in the literature $[13,14]$.

The electrochemical characteristics of the pristine $\mathrm{C}_{60}$ and $\mathrm{B}: \mathrm{C}_{60}$ films used as coating layers for silicon films were determined by cyclic voltammetry (CV) measurements. The aim of the $\mathrm{CV}$ tests is to investigate the reversible reaction between the lithium ions and silicon film as active materials. The $\mathrm{CV}$ curves of the pristine and $\mathrm{B}: \mathrm{C}_{60}$ coated silicon films at the first cycle at a scan rate of $0.05 \mathrm{mVs}^{-1}$ are shown in
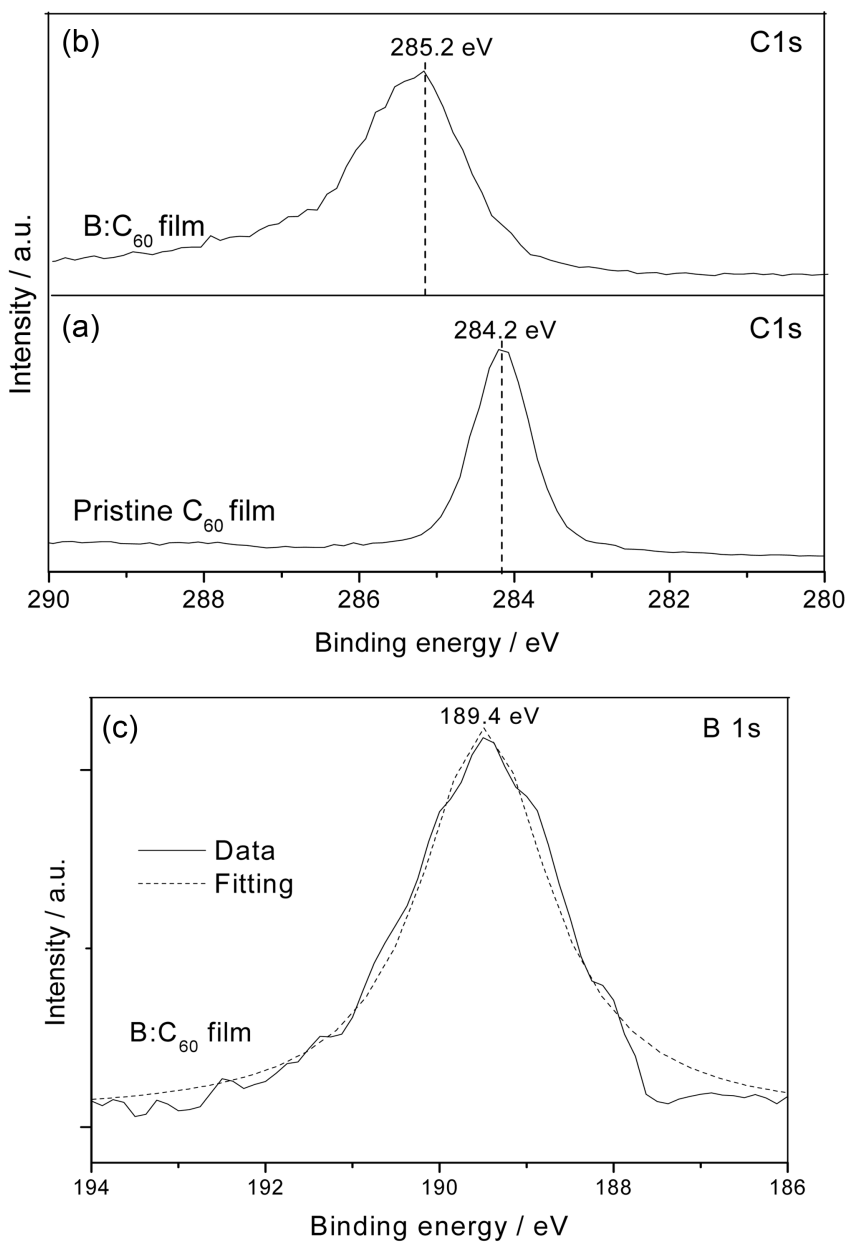

Fig. 5. XPS spectra of the (a) C 1s and (b) B 1s for pristine and $\mathrm{B}: \mathrm{C}_{60}$ films.

Fig. 6. For the pristine $\mathrm{C}_{60}$ coated silicon film, no anodic peaks are detected in the $\mathrm{CV}$ profiles. This indicates that the pristine $\mathrm{C}_{60}$ film blocks the insertion of lithium ions into the silicon film used as the active material during the chargedischarge tests. In contrast, the $\mathrm{B}: \mathrm{C}_{60}$ coated silicon film exhibits two pairs of cathodic and anodic peaks. It seems that the $\mathrm{B}: \mathrm{C}_{60}$ coating layer is effective in preserving the insertion and extraction of lithium ions during the chargedischarge tests. In other words, we can say that the $\mathrm{B}: \mathrm{C}_{60}$ coating layer is only acting as an inactive material during the electrochemical tests, the active host material for lithium accommodation is silicon, since the $\mathrm{CV}$ profiles of $\mathrm{B}: \mathrm{C}_{60}$ coated Si film is similar to that of bare Si film, as reported in our previous paper [15]. Additionally, the current intensity observed in the $\mathrm{CV}$ curve of the $\mathrm{B}: \mathrm{C}_{60}$ coated $\mathrm{Si}$ is higher than that of the pristine $\mathrm{C}_{60}$. Based on the $\mathrm{CV}$ results, it can be said that the effectiveness of the argon plasma treatment during the deposition of the $\mathrm{B}: \mathrm{C}_{60}$ film in preserving the reversible reaction between the lithium ions and silicon 


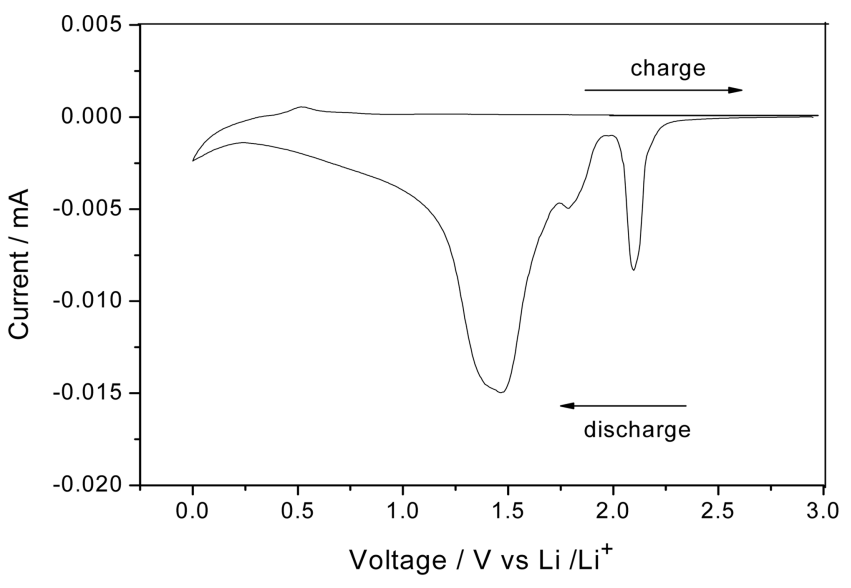

(a)

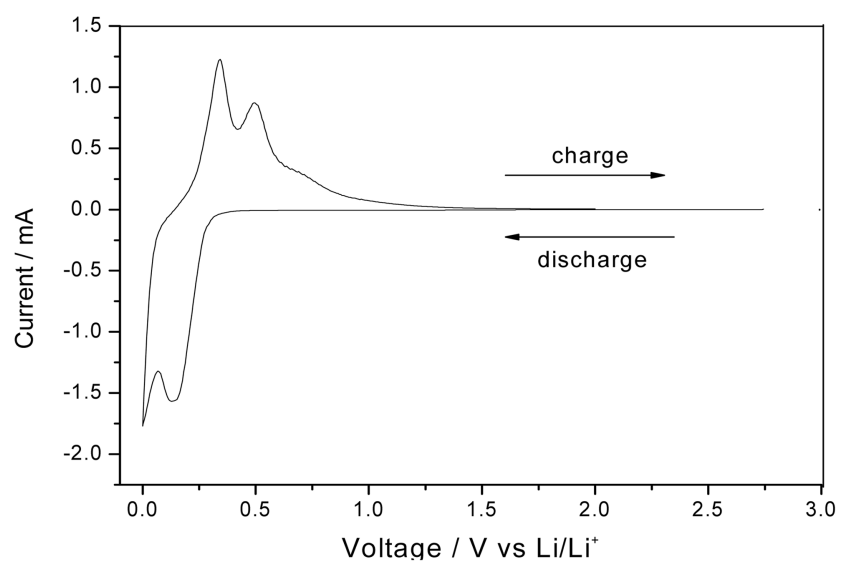

(b)

Fig. 6. Cyclic voltammetry curves of the (a) pristine coated $\mathrm{Si}$ and (b) $\mathrm{B}: \mathrm{C}_{60}$ coated $\mathrm{Si}$ electrodes at the first cycle under scan rate of $0.05 \mathrm{mVs}^{-1}$ between $0-3 \mathrm{~V}$.

anode is very significant since it may establish a better path for the transfer of lithium ions at the electrode/electrolyte interface.

\section{Conclusions}

In summary, boron doped fullerene $\left(B: C_{60}\right)$ thin films were successfully synthesized by a thermal evaporation technique assisted by argon plasma treatment. The presence of boron atoms in the fullerene lattices was confirmed by SEM, XPS and FTIR analysis. The $\mathrm{B}: \mathrm{C}_{60}$ film was then utilized as a coating layer for silicon anodes in lithium secondary batteries. The $\mathrm{CV}$ results indicated that $\mathrm{B}: \mathrm{C}_{60}$ was quite effective in preserving the reversible reaction between the lithium ions and silicon. The argon plasma treatment during the deposition of the $\mathrm{B}: \mathrm{C}_{60}$ film contributed to the formation of a passivation layer.

\section{References}

[1] Kroto, H. W.; Heath, J. R.; O'Brien, S. C.; Curl, R. F.; Smalley, R. E. Nature 1985, 318, 162.

[2] Ariciftci, N. S.; Braun, D; Zhang, C; Srdranov, V.; Heeger, A. J.; Wudl, F. Appl.Phys.Lett. 1993, 62, 385.

[3] Lee, J. Y.; Kwon, J. H. Appl.Phys.Lett. 2005, 86, 063514.

[4] Sun, Q; Wang, Q; Jena, P. Appl.Phys.Lett. 2009, 94, 3058678.

[5] Zou, Y. J.; Zhang, X. W.; Li, Y. L.; Wang, B.; Yan, H. J. Mat.Sci. 2002, 37, 1043.

[6] Zou, Y. J.; Li, Y. L.; Zhang, X. W.; Wang, B; Yan, H. Mat.Sci.Eng B 2001, 84, 163.

[7] Rao, A. M.; Zhou, P.; Wang, K; Hager, G. T.; Holden, J. M.; Wang, Y; Lee, W. T.; Bi, X. X.; Eklund, P. C.; Cornett, D. S.; Duncan, M. A.; Amster, I. J. Science 1993, 259, 955.

[8] Jin, Y.; Yao, C.; Wang, Z.; Xie, E.; Song, Y.; Sun, Y.; Zhang, C.; Liu, J.; Duan, J. Nuclear Instr and Meth. in Physics Research B 2005, 230, 565.

[9] Dresselhaus, M. S.; Dresselhaus, G.; Eklund, P. C. J. Raman Spect. 1996, 27, 351.

[10] Wagberg, T.; Jacobsson, P.; Sundqvist, B. Phys.Rev B. 1999, 60, 4536.

[11] Rao, A. M; Eklund, P. C.; Hodeau, J. L.; Marques, L.; Nunez Regueiro, M. Phys.Rev B. 1997, 55, 4766.

[12] Zou,Y. G.; Liu, B. B.; Yao, M. G.; Hou, Y. Y.; Wang, L.; Yu, S. D.; Wang, P.; Cui, T.; Zou, G. T.; Sundqvist, B.; Wang, G. R.; Lin, Y. C. Acta Phy. Sinica. 2007, 5172.

[13] Muhr, H. J.; Nesper, R.; Schnyder, B.; Kotz, R. Chem. Phys.Lett. 1996, 249, 399.

[14] Kunzli, H.; Gantenbein, P.; Steiner, R.; Oelhaven, P. J. Anal.Chem. 1993, 346, 41.

[15] Arie, A. A.; Chang, W.; Lee, J. K. J. Solid State Electrochem. 2010, 14, 51. 